\title{
Efeito da Densidade e dos Períodos de Convivência de Cyperus esculentus NA CULTURA DO ARROZ IRRIGADO ${ }^{1}$
}

\author{
Effect of Density and Coexistence Periods of Cyperus esculentus on Irrigated Rice Crop
}

\author{
ERASMO, E.A.L. ${ }^{2}$, COSTA, N.V. ${ }^{3}$, PINHEIRO, L.L.A. ${ }^{3}$, SILVA, J.I.C. ${ }^{3}$, TERRA, M. ${ }^{3}$, \\ SARMENTO, R.A. ${ }^{4}$, CUNHA, A.M. ${ }^{5}$ e GARCIA, S.L.R. ${ }^{6}$
}

\begin{abstract}
RESUMO - Este trabalho teve o objetivo de analisar o efeito competitivo de Cyperus esculentus sobre o desenvolvimento inicial da cultura do arroz irrigado. O experimento a campo foi conduzido em área de produção de arroz irrigado, na Estação Experimental da Universidade do Tocantins, em Formoso do Araguaia-TO. O delineamento estatístico utilizado foi um fatorial 4 x 5 com quatro repetições, em blocos ao acaso. Os tratamentos constaram de quatro densidades de C. esculentus (25, 50, 100 e 200 plantas $\mathrm{m}^{-2}$ e uma testemunha no limpo) e cinco períodos de convivência com o arroz $(15,25,35,45$ e 60 dias após a emergência). No final de cada período de convivência foram avaliados: matéria seca, área foliar, número de perfilhos e rendimento da cultura. C. esculentus afetou mais a cultura do arroz irrigado a partir dos 25 dias de convivência. Duzentas plantas de C. esculentus $\mathrm{m}^{-2}$, convivendo por um período de 35 dias, reduziram a produção em 20,11\%, representando 17,4 sacas ha ${ }^{-1}$. A matéria seca, a área foliar e o número de perfilhos por plantas de arroz foram afetados pela presença das plantas daninhas em todos os períodos de convivência, porém a área foliar foi a característica mais influenciada.
\end{abstract}

Palavras-chave: interferência, Cyperus, período de competição.

\begin{abstract}
This work aimed to analyze the competitive effect of Cyperus esculentus on the initial development of irrigated rice. The field experiment was carried out at the Experimental Station of the University of Tocantins, in Formoso do Araguaia-TO. The statistical design used was a $4 \times 5$ factorial scheme with four replications in randomized blocks. The treatments consisted of four densities of C. esculentus $\left(25,50,100,200\right.$ plants $\mathrm{m}^{2}$ and a clean check) and five periods of coexistence with rice $(15,25,35,45,60$ days after emergence). At the end of each period, dry matter, leaf area, number of tillers and rice yield were evaluated. C. esculentus presented higher irrigated rice yield reduction starting from 25 days of coexistence with the crop. Two hundred plants of C. esculentus $\mathrm{m}^{-2}$ coexisting for a period of 35 days reduced yield to $20.11 \%$, representing 17.4 sacs ha ${ }^{-1}$. Dry matter, leaf area and number of tillers per rice plant were affected by the weeds in all the coexistence periods, with the leaf area being the most affected crop parameter.
\end{abstract}

Key words: interference, Cyperus, competition period.

Recebido para publicação em 11.10.2002 e na forma revisada em 12.12.2003.

2 Universidade do Tocantins - Campus de Gurupi, Caixa Postal 66, 77400-000 Gurupi-TO. ${ }^{3}$ Eng.-Agrônomo. ${ }^{4}$ Estudante de Doutorado da Universidade Federal de Viçosa - UFV, 36570-000 Viçosa-MG, Brasil. ${ }^{5}$ Mestre em Solos e Nutrição de Plantas. ${ }^{6}$ Departamento de Informática, Faculdade de Viçosa. 


\section{INTRODUÇÃO}

O sucesso na exploração de determinada cultura agrícola está condicionado a uma série de fatores (controláveis ou não), que, na somatória dos seus efeitos, expressará em última análise a produção final. Dentre os fatores passiveis de controle encontram-se aqueles de caráter biótico, especificamente relacionados à interferência interespecífica implantada por outras espécies que surgem associadas aos cultivos.

Os diversos ecossistemas apresentam grande número de espécies daninhas, principalmente em áreas férteis e com abundância de água, como nas áreas de várzea, tornando essencial o seu manejo correto.

Dentro da diversidade de espécies freqüentes nas áreas de produção de arroz irrigado do Tocantins, semelhantemente ao que ocorre no Brasil e no mundo, destacam-se as espécies da família das Cyperaceas, principalmente Cyperus esculentus e Cyperus iria, devido à adaptação às condições próprias que as várzeas oferecem. A pressão exercida pelas plantas que crescem associadas à cultura do arroz estabelece uma competição pelos mesmos fatores de crescimento, luz, água, nutrientes e espaço, reduzindo, conseqüentemente, a produção final.

Segundo Smith (1983), muitas variáveis ecológicas e de práticas de produção de cultivo influenciam a presença e abundância das espécies daninhas em arrozais, como: o método de semeadura, o regime de umidade do solo, a rotação de cultivos, a preparação do solo, a fertilidade do solo, o cultivar semeado, o manejo da irrigação e a tecnologia de controle das plantas daninhas. O balanço competitivo entre as comunidades infestantes e as culturas agrícolas depende de fatores ligados à própria comunidade infestante (composição específica, densidade e distribuição), à cultura (espécie ou variedade, espaçamento e densidade de plantio) e à extensão da época de convivência, podendo estes fatores ser alterados pelas condições edafoclimáticas e pelos tratos culturais (Pitelli, 1985). Entre os fatores citados, a densidade de plantas, a época e a extensão do período de convivência destacam-se em importância, uma vez que estarão diretamente envolvidos nas tomadas de decisão quanto à utilização de herbicidas. De acordo com Amaral
(1995), 40 plantas de Cyperus esculentus $\mathrm{m}^{-2}$, convivendo com a cultura de arroz irrigado até a colheita, reduziram a produção de grãos em $38,5 \%$. Kelley \& Thullen (1987) observaram que 150 e 750 ciperáceas $\mathrm{m}^{-2}$ reduziram em 2 e $59 \%$ a produção de arroz, respectivamente. Deuber $\&$ Forster (1972) recomendam que a cultura do arroz irrigado deva ser mantida livre de competição com as plantas daninhas até 32 dias após a emergência, de maneira a não causar queda na produção.

O presente trabalho teve como objetivo avaliar o efeito do retardamento no controle de C. esculentus, bem como a influência deste associado à densidade de plantas daninhas presentes, sobre a produção econômica do arroz.

\section{MATERIAL E MÉTODOS}

O experimento foi instalado e conduzido em condições de campo, em área de produção de arroz irrigado, na Estação Experimental da Universidade do Tocantins, em Formoso do Araguaia-TO. O solo, classificado como Gley pouco húmico, foi preparado no sistema convencional, com uma passagem de grade pesada e duas leves. O cultivar utilizado foi Epagri 109, sendo o plantio realizado no ano agrícola 99/ 2000 , com $120 \mathrm{~kg} \mathrm{ha}^{-1}$ de sementes, num espaçamento entre linhas de $0,20 \mathrm{~m}$. A inundação da área ocorreu 35 dias após a emergência.

O experimento foi constituído de um fatorial 4 x 5 com quatro repetições, num delineamento de blocos casualizados. Os tratamentos constaram de quatro densidades de Cyperus esculentus $\left(25,50,100\right.$ e 200 plantas $\left.\mathrm{m}^{-2}\right)$ e cinco períodos de convivência $(15,25,35,45 \mathrm{e}$ 60 dias após a emergência), além de uma parcela adicional (totalmente no limpo durante todo o ciclo da cultura). Após cada período, as plantas de C. esculentus foram retiradas através de capinas, permanecendo a cultura no limpo até a colheita. Cada parcela constou de $15 \mathrm{~m}^{2}$ (5 x $\left.3 \mathrm{~m}\right)$, utilizando-se para efeito de amostragens e colheita as seis linhas centrais, respeitando-se um metro de cada borda da parcela. No final de cada período de convivência entre C. esculentus e a cultura do arroz irrigado, foram coletadas quatro plantas de arroz ao acaso por parcela, para a avaliação dos seguintes parâmetros: matéria seca da 
parte aérea; número de perfilhos; área foliar (AF) em $\mathrm{cm}^{2}$, obtida através da fórmula $\mathrm{AF}=$ $0,82 \times(\mathrm{CxL})$, segundo Bhan et al. (1966); e produção de grãos. O material coletado foi devidamente lavado e seco em estufa com circulação forçada de ar a $75{ }^{\circ} \mathrm{C}$ por um período de 24 horas até peso constante, sendo pesado posteriormente em balança de precisão. Os resultados obtidos foram submetidos à análise estatística de regressão e expressos em curvas, quando significativos.

\section{RESULTADOS E DISCUSSÃO}

As curvas de regressão referentes ao acúmulo de matéria seca por planta de arroz irrigado em função do período de convivência com diferentes densidades de C. esculentus estão expressas na Tabela 1. Observa-se que as equações que melhor se ajustaram às densidades de 0 (testemunha), 25 e 50 plantas $\mathrm{m}^{-2}$ foram as do tipo linear, enquanto nas densidades de 100 e 200 plantas $\mathrm{m}^{-2}$ as equações obedeceram aos modelos de regressão quadrática e cúbica, respectivamente.

O acúmulo de massa até 35 DAS é a característica mais importante na definição do potencial supressivo de plantas daninhas pelos cultivares (Ni et al., 2000). No presente estudo, foi observado que plantas de arroz, após um período de 25 dias de convivência (= DAE), demonstraram decréscimo no acúmulo da matéria seca, evidenciando, assim, o efeito da competição de C. esculentus. Foram constatados decréscimos no peso seco por planta de arroz, que conviveram numa densidade de 50 e 100 plantas $\mathrm{m}^{-2}$ de C. esculentus, num período de $35 \mathrm{DAE}$, na ordem de 15,6 e 19,8\%, respectivamente. A maior redução do peso seco foi obtida com a densidade de 200 plantas de C. esculentus por $\mathrm{m}^{2}$, em que se constatou decréscimo de $21,62 \%$ em um período de convivência de 60 dias, quando comparado com a testemunha (Figura 1).

$\mathrm{Na}$ evolução da área foliar das plantas de arroz irrigado em função do período de convivência com diferentes densidades de C. esculentus, expresso na Tabela 2, foram observadas diferenças na magnitude destas a partir dos 35 dias, ficando mais evidentes as diferenças a partir dos 45 dias de convivência com a planta daninha. A partir desse período, foram constatados decréscimos conforme o aumento na densidade de C. esculentus, sendo maiores $(39,46,40,67$ e 50,37\%) aos 60 dias de convivência, nas densidades de 50,100 e 200 plantas de C. esculentus $\mathrm{m}^{-2}$, respectivamente, quando comparado com a testemunha (Tabela 2). Esses decréscimos podem estar relacionados à velocidade do acúmulo de área foliar do cultivar utilizado, considerada de ciclo

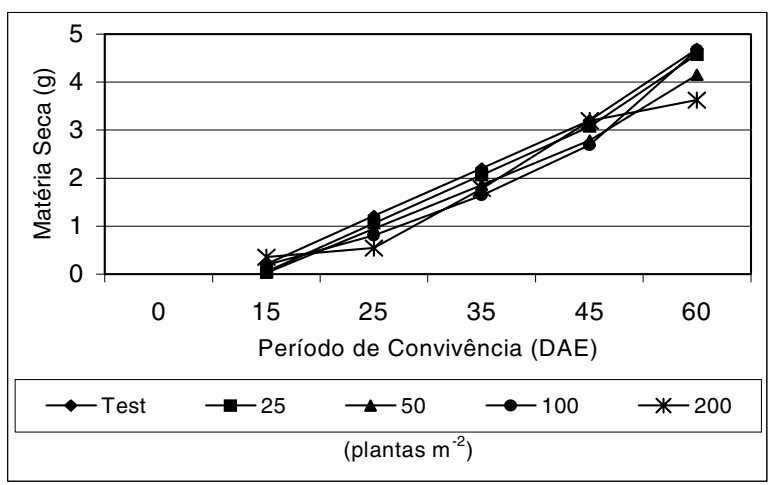

Figura 1 - Matéria seca por planta de arroz irrigado em função do período de convivência após a emergência (DAE), com diferentes densidades de Cyperus esculentus.

Tabela 1 - Equações de regressão correspondentes a cada curva de densidade de C. esculentus

\begin{tabular}{|c|c|c|}
\hline $\begin{array}{c}\text { Densidade } \\
\left({\left.\text { plantas } \mathrm{m}^{-2}\right)}\right.\end{array}$ & Equação & $\mathrm{R}^{2}$ \\
\hline Testemunha & $\hat{Y}=-0,128217 \mathrm{E}+01+0,9958811 \mathrm{E}-01 \mathrm{x}$ & 0,96 \\
\hline 25 & $\hat{Y}=-0,1449221 \mathrm{E}+01+0,1003811 \mathrm{E}+00 \mathrm{x}$ & 0,95 \\
\hline 50 & $\hat{Y}=-0,1333934 \mathrm{E}+01+0,9144262 \mathrm{E}-01 \mathrm{x}$ & 0,95 \\
\hline 100 & $\hat{Y}=-0,3268686 \mathrm{E}+00+0,1847198 \mathrm{E}-01 \mathrm{x}+0,1080765 \mathrm{E}-02 \mathrm{x}^{2}$ & 0,98 \\
\hline 200 & $\hat{Y}=0,4025 \mathrm{E}+01+-0,45781 \mathrm{E}+00 \mathrm{x}+0,16507 \mathrm{E}-01 \mathrm{x}^{2}+-0,14982 \mathrm{E}-3 \mathrm{x}^{3}$ & 0,97 \\
\hline
\end{tabular}


longo (Fleck et al., 2003; Altieri \& Liebman, 1988). Diferentes genótipos apresentam variadas velocidades de acúmulo de área foliar, o que os tornam mais competitivos ou não por luz no início do ciclo, aumentando ou diminuindo o sombreamento das plantas vizinhas (Garrity et al., 2001; Fleck et al., 2003).

O número de perfilhos das plantas de arroz irrigado, por ocasião da colheita, em função do período de convivência da cultura com as diferentes densidades de C. esculentus foi afetado no período inicial da competição (Tabela 3), logo aos 15 dias de convivência com as plantas daninhas, de acordo com o aumento da densidade de C. esculentus. As densidades de 25, 50,100 e 200 plantas de C. esculentus $\mathrm{m}^{-2}$ proporcionaram reduções no número de perfilhos na ordem de $16,92,17,92,24,08$ e $28,23 \%$, respectivamente, após 60 dias de convivência com a cultura do arroz irrigado.

O rendimento da cultura do arroz irrigado (Tabela 4), em função do período de convivência, e as diferentes densidades de C. esculentus evidenciaram que a produção de grãos $\left(\mathrm{kg} \mathrm{ha}^{-1}\right)$ sofreu influência do efeito de competição da planta daninha, após 25 dias iniciais de convivência. Esse efeito tornou-se ainda mais acentuado aos 35 dias de convivência, verificando-se reduções em torno de 20,06 e $20,11 \%$ para as densidades de 100 e 200 plantas de C. esculentus, respectivamente, representando, em média, uma perda de 17 sacas ha ${ }^{-1}$. Resultados semelhantes foram observados por Kelley \& Thullen (1987) e Alcântara (1999). Esses

Tabela 2 - Área foliar média de arroz, em $\mathrm{cm}^{2}$, plantado em diferentes densidades e em diferentes períodos de convivência com Cyperus esculentus

\begin{tabular}{|c|c|c|c|c|c|}
\hline Período de convivência & \multicolumn{5}{c|}{ Densidade (plantas ha ${ }^{-1}$ ) } \\
\hline (dias) & 25 & 50 & 100 & \multicolumn{2}{c|}{200} \\
\hline 15 & \multicolumn{7}{|c|}{ Testemunha no limpo $=625,32$} \\
\hline 25 & 233,90 & 324,56 & 476,09 & 685,36 & 429,98 \\
\hline 35 & 186,51 & 254,73 & 433,79 & 580,81 & 363,96 \\
\hline 45 & 175,72 & 288,94 & 400,26 & 460,75 & 331,42 \\
\hline 60 & 159,50 & 254,24 & 369,13 & 406,60 & 297,37 \\
\hline Média & 154,32 & 256,70 & 325,41 & 340,17 & 269,15 \\
\hline
\end{tabular}

$\hat{Y}=207,7210+4,3449 * * D-0,01144 * * D^{2}-3,4662 * * C \quad R^{2}=0,88$.

** Significativo a $1 \%$ de probabilidade pelo teste $\mathrm{t}$.

Tabela 3 - Número médio de perfilhos de arroz, plantado em diferentes densidades e em diferentes períodos de convivência com Cyperus esculentus

\begin{tabular}{|c|c|c|c|c|c|}
\hline \multirow{2}{*}{$\begin{array}{c}\text { Período de convivência } \\
\text { (dias) }\end{array}$} & \multicolumn{4}{|c|}{ Densidade (plantas ha ${ }^{-1}$ ) } & \multirow{2}{*}{ Média } \\
\hline & 25 & 50 & 100 & 200 & \\
\hline \multicolumn{6}{|c|}{ Testemunha no limpo $=3,30$} \\
\hline 15 & 3,07 & 2,80 & 3,07 & $2,46 *$ & 2,85 \\
\hline 25 & $2,73 *$ & $2,67 *$ & 2,87 & $2,40 *$ & 2,67 \\
\hline 35 & 2,80 & $2,53 *$ & $2,31 *$ & $2,27 *$ & 2,48 \\
\hline 45 & 3,00 & $2,60 *$ & 2,80 & $2,40^{*}$ & 2,70 \\
\hline 60 & $2,70 *$ & $2,67 *$ & $2,52 *$ & $2,33 *$ & 2,55 \\
\hline Média & 2,86 & 2,65 & 2,71 & 2,37 & \\
\hline
\end{tabular}

Estatisticamente diferente da testemunha pelo teste de Dunnett a 5\% de probabilidade. DMS $=0,15$.

$\hat{Y}=1,7507-0,0007452 * D-0,001591 * C \quad R^{2}=0,58$.

* e ** Significativo a 5 e $1 \%$ de probabilidade, respectivamente, pelo teste t. 
Tabela 4 - Produção média de arroz, em $\mathrm{kg} \mathrm{ha}^{-1}$, plantado em diferentes densidades e em diferentes períodos de convivência com Cyperus esculentus

\begin{tabular}{|c|c|c|c|c|c|}
\hline \multirow{2}{*}{$\frac{\text { Período de convivência }}{\text { (dias) }}$} & \multicolumn{4}{|c|}{ Densidade (plantas ha $^{-1}$ ) } & \multirow{2}{*}{ Média } \\
\hline & 25 & 50 & 100 & 200 & \\
\hline \multicolumn{6}{|c|}{ Testemunha no limpo $=5284,85$} \\
\hline 15 & $4.808 *$ & $4.876 *$ & $4.817 *$ & $4.413 *$ & 4.729 \\
\hline 25 & $4.886 *$ & $4.697 *$ & $4.774 *$ & $4.651 *$ & 4.752 \\
\hline 35 & $4.887 *$ & $4.580 *$ & $4.156 *$ & $4.152 *$ & 4.444 \\
\hline 45 & $4.630 *$ & $4.578 *$ & $3.950 *$ & $4.113 *$ & 4.318 \\
\hline 60 & $4.742 *$ & $4.432 *$ & $4.145 *$ & $4.064 *$ & 4.346 \\
\hline Média & 4.791 & 4.633 & 4.368 & 4.278 & \\
\hline
\end{tabular}

* Estatisticamente diferente da testemunha pelo teste de Dunnett a $5 \%$ de probabilidade. DMS $=313,38 \mathrm{~kg} \mathrm{ha}^{-1}$.

$\hat{Y}=5384,46-8,9840 * * D+0,02675 * * D^{2}-10,5387 * * C \quad R^{2}=0,74$

** Significativo a $1 \%$ de probabilidade pelo teste $\mathrm{t}$.

Tabela 5 - Resumo da análise de variância da produção, do número de perfilhos e da área foliar de arroz, plantado em diferentes densidades e nos diferentes períodos de convivência com Cyperus esculentus

\begin{tabular}{|c|c|c|c|c|c|}
\hline \multirow{2}{*}{$\mathrm{FV}$} & \multirow{2}{*}{ GL } & \multicolumn{2}{|c|}{ Quadrado médio } & \multirow{2}{*}{ GL } & \multirow{2}{*}{$\frac{\mathrm{QM}}{\text { Área foliar }}$} \\
\hline & & Produção & Perfilhos $^{\underline{1}}$ & & \\
\hline Blocos & 3 & $26.631,63$ & 0,0026 & 3 & 130,91 \\
\hline Tratamentos & $(20)$ & $487.057,40 * *$ & $0,0287 * *$ & . & $\cdot$ \\
\hline Fatorial & (19) & $394.806,87 * *$ & $0,0228 *$ & $(19)$ & $80.319,10 * *$ \\
\hline Densidade (D) & 3 & $1.115 .303,00 * *$ & $0,0773 * *$ & 3 & $378.200,50 * *$ \\
\hline Convivência (C) & 4 & $697.673,80 * *$ & $0,0314 *$ & 4 & $62.273,43^{* *}$ \\
\hline $\mathrm{D} \times \mathrm{C}$ & 12 & $113.727,20 * *$ & $0,0063 \mathrm{~ns}$ & 12 & $11.860,81 * *$ \\
\hline Fatorial vs testemunha & 1 & $2.239 .817,47 * *$ & $0,1408 * *$ & . & . \\
\hline Resíduo & 60 & $43.647,15$ & 0,0106 & 57 & 470,25 \\
\hline $\mathrm{CV}(\%)$ & & 4,59 & 6,32 & & 6,41 \\
\hline
\end{tabular}

** Significativo a $1 \%$ de probabilidade pelo teste $\mathrm{F}$., * significativo a $5 \%$ de probabilidade pelo teste $\mathrm{F}$ e ns não-significativo a $5 \%$ de probabilidade pelo teste $\mathrm{F} . \stackrel{1}{ }^{\prime}$ Valores transformados para $\sqrt{x}$.

mesmos autores mostraram um efeito negativo no rendimento de grãos, com 40 plantas de C. esculentus $\mathrm{m}^{-2}$ convivendo com a cultura de arroz irrigado até a colheita, ocasionando uma redução de grãos de 38,5\%. Pitelli (1985) obteve resultados semelhantes em experimento no campo, onde foram observadas reduções de 18,5 e $19,8 \%$ para as mesmas densidades de 100 e 200 plantas de C. esculentus. No periodo de convivência de 60 dias com as mesmas densidades de plantas daninhas, essa redução na produção de grãos foi em média de $22 \%$, o que correspondeu a uma perda em média de 19 sacas ha-1.

Deuber \& Forster (1972) observaram reduções de 25,3 e $28,4 \%$ para as densidades de
100 e 150 plantas de C. esculentus, respectivamente. Os mesmos autores recomendam que a cultura do arroz irrigado deve crescer livre da competição pelas plantas daninhas até 32 dias a partir da emergência, de maneira a não sofrer queda na produção.

Uma análise conjunta dos diferentes parâmetros mostrou relações comuns entre as variáveis estudadas (Tabela 5). O efeito da competição proporcionada pela Cyperacea intensificou-se praticamente a partir dos 35 dias após a emergência da cultura, com decréscimos crescentes até o final do período experimental, sendo mais evidente nas maiores densidades (100 e 200 plantas de C. esculentus por $\mathrm{m}^{2}$ ) e nos maiores períodos 
de convivência. Efeitos significativos foram constatados na redução da área foliar, bem como no menor acúmulo de matéria seca por planta em decorrência da redução do número de perfilhos. Dados semelhantes foram verificados por Erasmo et al. (2000) na fase inicial de competição entre $C$. esculentus e arroz irrigado em casa de vegetação, com redução de $27 \%$ da área foliar das plantas de arroz, numa densidade de 8 tubérculos por vaso, correspondente a 286 plantas $\mathrm{m}^{-2}$ num período de 60 DAE de convivência. Os mesmos autores observaram que, além da redução de 15 e 26\% no número de perfilhos com a presença de $4 \mathrm{e}$ 8 tubérculos por vaso, num período de convivência de 45 dias ocorreu também redução na matéria seca da planta.

O maior efeito supressor exercido pela planta daninha a partir dos 25 e 35 dias de convivência pode ser explicado pela coincidência das épocas da aplicação da adubação nitrogenada, que possivelmente favoreceram a infestação da Cyperacea, potencializando sua agressividade natural em relação à competição por nutrientes, em pleno florescimento, além do efeito alelopático referente a esta espécie, já confirmado por Drost \& Doll (1980), e da época de maior intensidade de crescimento vegetal das plantas de arroz, representado pelo surgimento de perfilhos, normalmente compreendido entre os 15 e 60 dias após a emergência da cultura.

Os resultados experimentais alertam para os prejuízos potenciais em relação ao atraso no emprego do controle da espécie $C$. esculentus na cultura do arroz irrigado.

\section{LITERATURA CITADA}

ALTIERI, M. A.; LIEBMAN, M. Weed management in agroecosystems: ecological approaches. Boca Raton: CRC Press, 1988. 354 p.

AMARAL, A. S. Controle químico de ciperáceas na cultura do arroz irrigado. Lav. Arrozeira, v. 48, n. 420, p. 3-6, 1995.
ALCÂNTARA, E. N. Controle de plantas daninhas na cultura do arroz. Inf. Agrop., v. 14, n. 161, p. 40-44, 1999.

BHAN, V. M.; TRENBATH, B. R.; ROUSH, M. L. Measurement of leaf area of rice. Agron. J., v. 58, p. 454, 1966.

DROST, D. C.; DOLL, J. D. The allelophatic effect of yellow nutsedge (Cyperus esculentus) on corn and soybean. Weed Sci., v. 28, p. 229-233, 1980.

DEUBER, R.; FORSTER, R. Cultivo e competição ervas na cultura do arroz (Oryza sativa). In: SEMINÁRIO BRASILEIRO DE HERBICIDAS E ERVAS DANINHAS, 9., Campinas, SBHED, 1972. Anais... Campinas: SBHED, 1972. p. 20.

ERASMO, E. A. L. et al. Competição inicial entre Cyperus esculentus e arroz irrigado em condições de casa de vegetação. Planta Daninha, v. 18, n. 2, p. 301-307, 2000.

FLECK, N. G. et al. Características de plantas de cultivares de arroz irrigado relacionadas à habilidade competitiva com plantas concorrentes. Planta Daninha, v. 21, n. 1, p. 97104, 2003.

GARRITY, D. P.; MOVILLON, M.; MOODY, K. Differential weed suppression ability in upland rice cultivars. Agron. J., v. 93, n. 3, p. 326-332, 2001.

KELLEY, P. E.; THULLEN, R. J. Light requirements of yellow nutseage and light interception by crops. Weed Sci., v. 26, n. 1, p. 10-16, 1987.

NI, H. et al. Oryza sativa plant traits conferring competitive ability against weeds. Weed Sci., v. 48, n. 2, p. 200-204, 2000.

PITELLI, R. A. Interferência de plantas daninhas em culturas agrícolas. Inf. Agropec., v. 11, n. 129, p. 16-17, 1985.

SMITH, R. J. Weeds of major economic importance in rice and yield losses due to weed competition. In: CONFERENCE ON WEED CONTROL IN RICE, Philipines, Los Baños, 1983. Proceedings... Los Baños: IRRI, 1983. p. 19-36. 